\title{
Treatment of liver metastases in patients selected for cytoreductive surgery and hyperthermic intraperitoneal chemotherapy for colorectal peritoneal carcinomatosis
}

\author{
Antonio Sommariva \\ Surgical Oncology Unit, Veneto Institute of Oncology IOV - IRCCS, 35128 Padova, Italy.
}

Correspondence to: Dr. Antonio Sommariva, Surgical Oncology Unit, Veneto Institute of Oncology IOV - IRCCS, via Gattamelata 64, 35128 Padova, Italy. E-mail: antonio.sommariva@iov.veneto.it

How to cite this article: Sommariva A. Treatment of liver metastases in patients selected for cytoreductive surgery and hyperthermic intraperitoneal chemotherapy for colorectal peritoneal carcinomatosis. J Cancer Metastasis Treat 2017;3:362-7.

Article history:

Received: 25 May 2017

First Decision: 19 Sep 2017

Revised: 9 Oct 2017

Accepted: 20 Oct 2017

Published: 21 Dec 2017

Key words:

Colorectal cancer, peritoneal carcinomatosis,

liver metastases,

hyperthermic intraperitoneal

chemotherapy,

liver resection

\section{ABSTRACT}

Cytoreductive surgery (CS) and hyperthermic intraperitoneal chemotherapy (HIPEC) have gained increasing consensus in treatment of peritoneal carcinomatosis from colorectal cancer. The presence of liver metastases is generally considered a contraindication for CS + HIPEC, as hepatic involvement no longer represents a loco-regional aspect of disease. Despite this, liver resection (LR) has been tested in selected cases in combination with CS + HIPEC for treatment of peritoneal carcinomatosis with liver metastasis. Relevant studies on this topic were identified through a search in the electronic PubMed database, using the appropriate keywords. CS + HIPEC + LR allows similar outcomes in terms of survival and morbidity with respect to CS + HIPEC, especially in patients with low tumor load. CS + HIPEC + LR represents a reasonable approach for patients with peritoneal carcinomatosis and liver metastases from colorectal cancer. Patients should be selected in high volume tertiary centres, preferably in the context of a prospective trial.

\section{INTRODUCTION}

Peritoneal carcinomatosis (PC) from colorectal carcinoma is present in about $10 \%$ of patients at the time of diagnosis, and appears in $25 \%$ of patients during follow-up ${ }^{[1,2]}$. Median survival of patients affected by colorectal peritoneal carcinomatosis varies between 5 and 7 months ${ }^{[3]}$. The introduction of systemic chemotherapy treatment regimes, based on oxaliplatin and irinotecan alone or associated with vascular endothelial growth factor (VEGF)-inhibitors (in various combinations and treatment sequences), has enabled a significant improvement in outcome for patients with metastatic colorectal cancer (MCC), where in some trials a median survival greater than

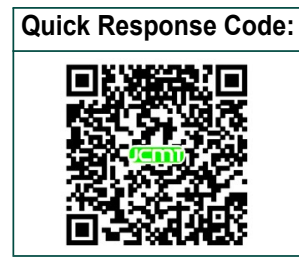


20 months has been obtained ${ }^{[4]}$. However, all the data presently available refer to patients with un-specified metastatic disease (liver, lung, peritoneum) and the role of modern systemic chemotherapy for treatment of isolated PC has been adequately investigated in only a few retrospective studies ${ }^{[5-7]}$.

The role of radical surgery for MCC has gained increasing attention in the oncological community and has been proposed in selected cases for liver ${ }^{[8]}$, lung $^{[9]}$ and peritoneal metastases ${ }^{[10]}$. Although the role of surgery in presence of multiple sites of MCC is almost un-explored, the combined and/ or sequential resection of liver, lymph nodes, lung metastases in various combinations has been tested with encouraging outcomes in very selected cases $^{[11]}$. Radical surgery for concomitant liver and extra-hepatic MCC has shown results that seem comparable to those obtained for isolated hepatic metastase $^{[12-15]}$. For colorectal liver metastases (LM), radical surgery offers a chance of cure in at least $17 \%$ of patients and liver resection (LR) has become the standard treatment for patients with resectable disease ${ }^{[16]}$. In isolated PC, the role of surgery is less defined and is generally restricted in the context of the multimodal approach of cytoreductive surgery (CS) + hyperthermic intraperitoneal chemotherapy (HIPEC), which appears as the only chance of cure in selected patients ${ }^{[17-20]}$. CS + HIPEC has been shown to be superior over systemic chemotherapy in one randomized controlled trial ${ }^{[17]}$ and in several uncontrolled studies that reported a median overall survival of 33 months and 5 -year survival of $43 \%{ }^{[7]}$. Patients with low tumor load and in whom a complete cytoreduction (CCR-0) is obtainable are those who benefit most from CS + HIPEC ${ }^{[18,19]}$, but research for further selection criteria (clinical and biological) is still ongoing.

Until a few years ago, the presence of peritoneal carcinomatosis with concomitant liver metastases was considered an absolute contraindication to CS + HIPEC and these patients were referred for systemic palliative treatment. The coexistence of liver metastases (haematogenous metastases) and peritoneal metastases (loco-regional metastases) was considered not amenable to curative surgical treatment due to the spread of the disease and to the complexity of a combined surgical approach. In the last decade a growing number of publications have reported patients treated with CS + HIPEC and $L R$, but it is still not clear which patients should be selected for this surgical approach.

\section{SURGERY FOR PERITONEAL AND LIVER MCC}

The introduction of oxaliplatin/irinotecan and VEGF inhibitors based chemotherapy has improved response rate and prolonged overall survival of patients with $M_{C C}{ }^{[4]}$. Despite that the absolute survival benefit obtained with modern systemic chemotherapy has been constantly increasing and the expected median survival of more than 20 months is predictable, surgical approach to MCC has gained increasing interest and LR has become the only chance of cure for resectable liver metastases ${ }^{[16]}$. Although early experience has identified patients with LM associated with extra-hepatic disease as a group with a poor prognosis, surgery for limited and stable disease has been frequently offered to patients with lung, peritoneal and other site metastases ${ }^{[11]}$. Small series of patients suggest that resection of the liver combined with other sites can offer a survival benefit, but the argument is still under investigation and the results of the few available studies are influenced by a high selection bias.

Data on surgery for peritoneal and liver MCC are very limited. Although, in one study, patients who underwent liver and extra-hepatic disease resection seem to have a worse prognosis ${ }^{[14]}$, a single center experience reported a $28 \% 5$-year survival rate in patients who underwent an R0 resection of extrahepatic disease simultaneously with hepatectomy for colorectal liver metastasis ${ }^{[12]}$. Unexpected peritoneal disease at time of planned liver resection was estimated in $3 \%$ of cases in a large single center experience ${ }^{[21]}$. After multivariate analysis, risk factors for peritoneal implants in this subset of patients were previous peritoneal carcinomatosis, T4 primary tumor and bilobar LM. In patients with completely resected and limited PC (PCI less than 2 ), the 5 -year overall survival was $18 \%$ with a median survival of 42 months, regardless of the extent of LM. These findings suggest that an accurate preoperative radiological evaluation not only of the liver but also of the peritoneal cavity is warranted, based on the risk of peritoneal implants (primary T4, resected PC or bilobar LM). Laparoscopic evaluation before surgery for colorectal LM combined with PC should be considered after a complete and accurate radiologic work-up, considering that the occurrence of unresectable disease is $5 \%$ inpatients selected for liver resection only ${ }^{[22]}$. Diagnostic laparoscopy to discover peritoneal implants should be selectively considered in groups undergoing surgery for LM, as the efficacy to discover peritoneal disease is very high $^{[23]}$. This allows the selection of patients for the 
Table 1: Comparative studies of CS + HIPEC \pm LR for peritoneal carcinomatosis and liver metastases from colorectal cancer

\begin{tabular}{lcccccc}
\hline & $\begin{array}{c}\text { Study } \\
\text { period }\end{array}$ & $\begin{array}{c}\text { Study sample } \\
\text { Studies } \\
\text { metastasis) }\end{array}$ & $\begin{array}{c}\text { Peritoneal } \\
\text { load } \\
\text { (PCI) }\end{array}$ & $\begin{array}{c}\text { Liver } \\
\text { metastases } \\
\text { (median } \\
\text { and range) }\end{array}$ & $\begin{array}{c}\text { Major } \\
\text { hepatectomy } \\
(\boldsymbol{n})\end{array}$ & $\begin{array}{c}\text { Ablative } \\
\text { techniques } \\
(\boldsymbol{n})\end{array}$ \\
\hline $\begin{array}{l}\text { Wake Forest University } \\
\text { Winston-Salem, USA }\end{array}$ & $1991-2007$ & $14 / 142(9 \%)$ & NR & $1(1-7)$ & 1 & 6 thermal cryo \\
ablation, \\
4 cryotherapy, \\
Uppsala University, Sweden
\end{tabular}

^Mean. CS: cytoreductive surgery; HIPEC: hyperthermic intraperitoneal chemotherapy; LR: liver resection; PCI: peritoneal cancer index; NR: not reported

more appropriate treatments and directs the group with limited peritoneal carcinomatosis to a more appropriate approach with HIPEC.

\section{PATIENT SELECTION FOR CS + HIPEC + LR}

For colorectal peritoneal carcinomatosis, cytoreductive surgery, normally adopted in the context of a multimodal approach of surgery followed by intraperitoneal chemotherapy, offer a significant survival advantage in selected patients treated in a high volume tertiary center ${ }^{[24]}$. Surgery, which represents the first step of the procedure, was standardized twenty years ago and consists of visceral resections and peritonectomies in various combinations ${ }^{[10]}$. The main surgical goal is to obtain an optimal cytoreduction with a macroscopic residual disease of less than $2.5 \mathrm{~mm}$. Intraperitoneal drug is delivered intra-operatively under hyperthermic conditions after completion of CS (HIPEC) $)^{[25]}$. The more important prognostic factor for patient selection for CS + HIPEC are the grade of cytoreduction and the peritoneal tumor load ${ }^{[19,20]}$. Although a locoregional approach, CS + HIPEC has been considered contraindicated in the presence of systemic disease and patients with peritoneal carcinomatosis and liver metastases were usually deemed not suitable for treatment and referred to oncologist for systemic chemotherapy.

The encouraging data on the curative role of surgery for liver metastases made CS + HIPEC combined with liver resection a less stringent contraindication ${ }^{[18,20]}$. Over the last few years, an increasing number of studies investigated the role of LR in patients selected for CS + HIPEC ${ }^{[26-28]}$. In some cases, the treatment of LM was done after intra-operative finding ${ }^{[28]}$, but in the majority of cases resection was planned with respect to pre-operative staging. In a few cases, liver metastases and peritoneal carcinomatosis treatment were sequential, performing liver resection after CS + HIPEC.

Patients selected for CS + HIPEC + LR presented with limited liver disease, as suggested by the median number of nodules (in general between 1 and 2), the rare occurrence of major resection and the frequent use of ablative techniques (cryotherapy, radiofrequency $)^{[20,29-32]}$ [Table 1 and Figure 1]. On the other hand, peritoneal load probably reflects the same tumor diffusion of patients selected for CS + HIPEC only, where a $\mathrm{PCl}$ index less than 20 is considered by the majority of referral centers as the preoperative cut-off value in selecting patients for treatment.

Analysing the prognostic factor, peritoneal and liver tumor load seems to have the most important impact on outcome. These data are in concordance with previous reports on surgical treatment of multiple sites MCC; the presence of multiple extra-hepatic site and more than five liver metastasis were the only two variables correlated with survival ${ }^{[14]}$. More recently a tumor load-based nomogram have been proposed for patients with potentially resectable synchronous peritoneal and liver metastases ${ }^{[20]}$. Although not yet prospectively validated, this simple nomogram combines as prognostic predictors the number of $\mathrm{LM}$ and the $\mathrm{PCl}$ and represents an interesting decision-making tool that could aid clinicians during multidisciplinary discussion to evaluate the most appropriate treatment.

\section{ASSESSMENT OF MORBIDITY AND MORTALITY}

An important issue arises from the potential increase in morbidity and mortality of combining CS + HIPEC to $L R$, both considered two surgical procedures 
Table 2: Studies comparing outcomes of CS + HIPEC alone vs. CS + HIPEC + LR in peritoneal carcinomatosis with or without liver metastases from colorectal cancer

\begin{tabular}{|c|c|c|c|c|c|c|c|c|c|}
\hline Studies & $\begin{array}{c}\text { Follow-up } \\
\text { (months) }\end{array}$ & $\begin{array}{c}\text { 2-year } \\
\text { survival } \\
(\%)\end{array}$ & $\begin{array}{c}\text { 3-year } \\
\text { survival } \\
(\%)\end{array}$ & $\begin{array}{c}\text { 4-year } \\
\text { survival } \\
(\%)\end{array}$ & $\begin{array}{c}\text { 5-year } \\
\text { survival } \\
(\%)\end{array}$ & $\begin{array}{c}\text { Median } \\
\text { survival } \\
\text { (months) }\end{array}$ & $\begin{array}{l}\text { Morbidity } \\
\text { (\%) }\end{array}$ & $\begin{array}{c}\text { Mortality } \\
\text { (\%) }\end{array}$ & $\begin{array}{c}\text { Prognostic } \\
\text { factors }\end{array}$ \\
\hline $\begin{array}{l}\text { Wake Forest } \\
\text { University } \\
\text { Winston-Salem, } \\
\text { USA }^{[29]}\end{array}$ & 20.7 vs. 13.4 & 43.3 vs. 26.8 & NR & $\begin{array}{c}14.4 \% \text { Vs. } \\
17.4 \%\end{array}$ & NR & 23.0 vs. 15.8 & 40.1 vs. 57.1 & 7.1 vs. 7.7 & NR \\
\hline $\begin{array}{l}\text { Uppsala } \\
\text { University, } \\
\text { Sweden }^{[30]}\end{array}$ & 45 vs. 57 & NR & 47 vs. 30 & NR & NR & 34.0 vs. 15 & 27 vs. 27 & 9.0 vs. 0 & R1 resection \\
\hline $\begin{array}{l}\text { Gustave- } \\
\text { Roussy Institute, } \\
\text { France }^{[20]}\end{array}$ & 62.4 & NR & 54 vs. 36.5 & NR & 43.6 vs. 26.4 & NR & 17 vs. 41 & 4.2 vs. 8.1 & $\begin{array}{c}\mathrm{PCI} \text {, number } \\
\text { of } \mathrm{LM} \text {, type of } \\
\text { surgery }\end{array}$ \\
\hline $\begin{array}{l}\text { St George } \\
\text { Hospital, Sidney, } \\
\text { Australia }^{[31]}\end{array}$ & 19 & 65 vs. 68 & NR & NR & NR & 22.1 & 38.5 vs. 12.5 & 0 & NR \\
\hline $\begin{array}{l}\text { Université } \\
\text { Catholique } \\
\text { de Louvain, } \\
\text { Belgium }^{[32]}\end{array}$ & 34.2 & 89.5 vs. 70.2 & NR & NR & NR & 59.2 & 15.4 vs. 32 & 0 vs. 4 & NR \\
\hline
\end{tabular}

CS: cytoreductive surgery; HIPEC: hyperthermic intraperitoneal chemotherapy; LR: liver resection; PCl: peritoneal cancer index; LM: liver metastases; NR: not reported

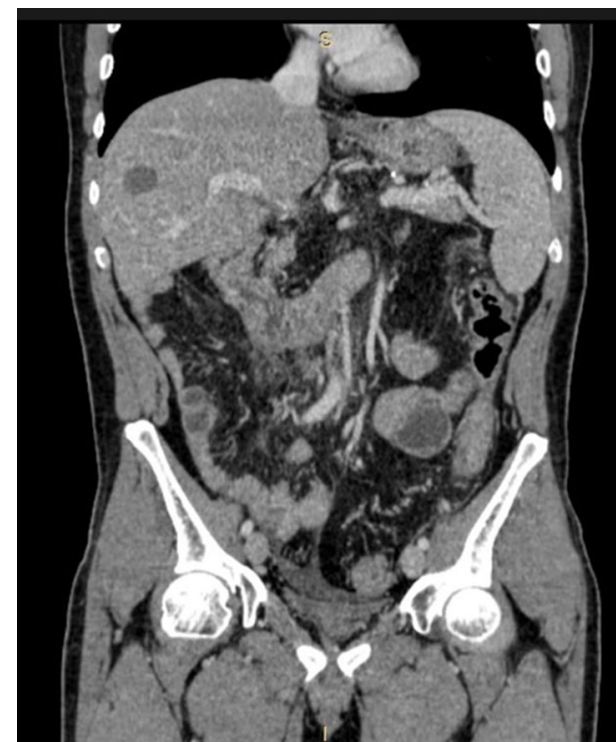

Figure 1: Colorectal peritoneal carcinomatosis and liver metastases (VII segment). Computed tomography performed 3 months after cytoreductive surgery + hyperthermic intraperitoneal chemotherapy combined with radiofrequency ablation

associated with a high risk of complications. The overall postoperative morbidity rate ranged from $14.8 \%$ to $58 \%{ }^{[33]}$. Due to improved surgical techniques, newer dissectors, increased anesthesiological skills and, most of all, refined selection criteria, the mortality and morbidity rates after CS + HIPEC have decreased during the last decade and postoperative outcomes are similar to a major gastrointestinal surgery ${ }^{[4]}$. In the same way, the mortality rates for liver resection, which was traditionally considered as one of the surgical procedures with the highest risk of death, have been lowered even more: for instance, recent series reported mortality rates less than $2 \%$, comparable to those observed after surgery for rectal cancer ${ }^{[34,35]}$. CS + HIPEC + LR does not seem to give an additional risk of complication as the morbidity and mortality seems similar with respect to CS + HIPEC alone ${ }^{[20,29-32]}$ [Table 2]. No study has reported a clear distinction between complication/mortality rate related to the liver resection or to the cytoreductive surgery. It should be underlined, however, that the reported LR combined with CS + HIPEC are classified as minor procedures, normally associated with lower risk of complications. Although no liver specific complications (biloma, bleeding, abscess) are generally reported, a higher risk of systemic toxicity has been noted after major $\mathrm{LR}^{[36]}$; the hypothesis that transient liver failure leads to a decreased drug inactivation and therefore a higher systemic toxicity should be further tested.

\section{SURVIVAL OUTCOME}

In retrospective studies investigating the role of CS + HIPEC + LR, the procedure resulted in a median survival between 15 and 23 months, a little worse with respect to the one reported for CS + HIPEC alone ${ }^{[20,29-32]}$. Also, in a comparative retrospective analysis of single centers, the 2-year overall survival seems lower when liver metastases are treated at the time of CS + HIPEC, ranging $43.3-89.5 \%$ for CS + HIPEC alone, and $26.8-70.2 \%$ for CS + HIPEC combined with $\mathrm{LR}^{[30-32]}$ [Table 2]. However, in the most relevant comparative study, no significant difference is detected between the treated groups ${ }^{[20]}$.

These findings appear in contradiction with the anatomic basis of colorectal cancer spread: 
peritoneal and liver metastases arise from different ways of diffusion (loco-regional vs. haematogenous), probably reflecting a different cancer cell genetics or epigenetic alterations; as previously hypothesized, a curative surgical resection for cancer is only cytoreductive surgery: surgery removes all detectable disease, but does not completely eradicate all tumor cells, since micro-metastases and circulating tumor cells are present in the blood of colorectal cancer patients after radical primary tumor resection in one third of all patients ${ }^{[36]}$. The fact that survival after HIPEC is not lowered by concomitant liver resection adds an important piece of evidence supporting this hypothesis that needs to be confirmed by more evidence.

\section{CONCLUSION}

The reported data confirmed that CS-HIPEC allows the achievement of long-term survival in patients usually referred for palliative systemic treatment. Although an advantage of HIPEC in terms of oncological outcome over systemic treatments has been not yet clearly proven, patients with no macroscopic residual disease, low peritoneal tumor load and few liver metastases seem to be the best indicated for CS + HIPEC + LR. CS + HIPEC associated with LR have mortality and morbidity rates similar to that observed with CS + HIPEC alone, although major hepatectomy has rarely been performed. For these reasons patients with peritoneal carcinomatosis and liver metastases from colorectal cancer should be referred to a tertiary center for selection of the more appropriate treatment, possibly within clinical trials.

\section{DECLARATIONS}

\section{Authors' contributions}

A. Sommariva contributed solely to the paper.

\section{Financial support and sponsorship} None.

\section{Conflicts of interest}

There are no conflicts of interest.

\section{Patient consent}

The patient of the computed tomography scan of Figure 1 gave his consent for publication.

\section{Ethic approval \\ Not applicable.}

\section{REFERENCES}

1. Sadeghi B, Arvieux C, Glehen O, Beaujard AC, Rivoire M, Baulieux J, Fontaumard E, Brachet A, Caillot JL, Faure JL, Porcheron J, Peix JL, François Y, Vignal J, Gilly FN. Peritoneal carcinomatosis from nongynecologic malignancies: results of the EVOCAPE 1 multicentric prospective study. Cancer 2000;88:358-63.

2. Jayne DG, Fook S, Loi C, Seow-Choen F. Peritoneal carcinomatosis from colorectal cancer. Br J Surg 2002;89:1545-50.

3. Chu DZ, Lang NP, Thompson C, Osteen PK, Westbrook KC. Peritoneal carcinomatosis in nongynecologic malignancy. A prospective study of prognostic factors. Cancer 1989;63:364-7.

4. Golfinopoulos V, Salanti G, Pavlidis N, Ioannidis JP. Survival and disease-progression benefits with treatment regimens for advanced colorectal cancer: a meta-analysis. Lancet Oncol 2007;8:898-911.

5. Chua TC, Morris DL, Saxena A, Esquivel J, Liauw W, Doerfer J, Germer CT, Kerscher AG, Pelz JO. Influence of modern systemic therapies as adjunct to cytoreduction and perioperative intraperitoneal chemotherapy for patients with colorectal peritoneal carcinomatosis: a multicenter study. Ann Surg Oncol 2011;18:1560-7.

6. Elias D, Lefevre JH, Chevalier J, Brouquet A, Marchal F, Classe JM, Ferron G, Guilloit JM, Meeus P, Goéré D, Bonastre J. Complete cytoreductive surgery plus intraperitoneal chemohyperthermia with oxaliplatin for peritoneal carcinomatosis of colorectal origin. $J$ Clin Oncol 2009;27:681-5.

7. Chua TC, Esquivel J, Pelz JO, Morris DL. Summary of current therapeutic options for peritoneal metastases from colorectal cancer. $J$ Surg Oncol 2012;107:566-73.

8. Nordlinger B, Sorbye H, Glimelius B, Poston GJ, Schlag PM, Rougier P, Bechstein WO, Primrose JN, Walpole ET, Finch-Jones M, Jaeck D, Mirza D, Parks RW, Collette L, Praet M, Bethe U, Van Cutsem E, Scheithauer W, Gruenberger T; EORTC Gastro-Intestinal Tract Cancer Group; Cancer Research UK; Arbeitsgruppe Lebermetastasen und-tumoren in der Chirurgischen Arbeitsgemeinschaft Onkologie (ALM-CAO); Australasian Gastro-Intestinal Trials Group (AGITG); Fédération Francophone de Cancérologie Digestive (FFCD). Perioperative chemotherapy with FOLFOX4 and surgery versus surgery alone for resectable liver metastases from colorectal cancer (EORTC Intergroup trial 40983): a randomised controlled trial. Lancet 2008;371:1007-16.

9. Yedibela S, Klein P, Feuchter K, Hoffmann M, Meyer T, Papadopoulos T, Göhl J, Hohenberger W. Surgical management of pulmonary metastases from colorectal cancer in 153 patients. Ann Surg Oncol 2006;13:1538-44.

10. Sugarbaker PH, Jablonski KA. Prognostic features of 51 colorectal and 130 appendiceal cancer patients with peritoneal carcinomatosis treated by cytoreductive surgery and intraperitoneal chemotherapy. Ann Surg 1995;221:124-32.

11. Carpizo DR, D'Angelica M. Liver resection for metastatic colorectal cancer in the presence of extrahepatic disease. Ann Surg Oncol 2009;16:2411-21.

12. Elias D, Sideris L, Pocard M, Ouellet JF, Boige V, Lasser P, Pignon JP, Ducreux M. Results of R0 resection for colorectal liver metastases associated with extrahepatic disease. Ann Surg Oncol 2004;11:27480 .

13. Elias D, Liberale G, Vernerey D, Pocard M, Ducreux M, Boige V, Malka D, Pignon JP, Lasser P. Hepatic and extrahepatic colorectal metastases: when resectable, their localization does not matter, but their total number has a prognostic effect. Ann Surg Oncol 2005; 12:900-9.

14. Aoki T, Umekita N, Tanaka S, Noda K, Warabi M, Kitamura M. Prognostic value of concomitant resection of extrahepatic disease in patients with liver metastases of colorectal origin. Surgery 
2008;143:706-14.

15. Byam J, Reuter NP, Woodall CE, Scoggins CR, McMasters KM, Martin RC. Should hepatic metastatic colorectal cancer patients with extrahepatic disease undergo liver resection/ablation? Ann Surg Oncol 2009;16:3064-9.

16. Tomlinson JS, Jarnagin WR, DeMatteo RP, Fong Y, Kornprat P, Gonen M, Kemeny N, Brennan MF, Blumgart LH, D’Angelica M. Actual 10-year survival after resection of colorectal liver metastases defines cure. J Clin Oncol 2007;25:4575-80.

17. Verwaal VJ, van Ruth S, de Bree E, van Sloothen GW, van Tinteren $\mathrm{H}$, Boot H, Zoetmulder FA. Randomized trial of cytoreduction and hyperthermic intraperitoneal chemotherapy versus systemic chemotherapy and palliative surgery in patients with peritoneal carcinomatosis of colorectal cancer. J Clin Oncol 2003;21:3737-43.

18. Glehen O, Kwiatkowski F, Sugarbaker PH, Elias D, Levine EA, De Simone M, Barone R, Yonemura Y, Cavaliere F, Quenet F, Gutman M, Tentes AA, Lorimier G, Bernard JL, Bereder JM, Porcheron J, Gomez-Portilla A, Shen P, Deraco M, Rat P. Cytoreductive surgery combined with perioperative intraperitoneal chemotherapy for the management of peritoneal carcinomatosis from colorectal cancer: a multi-institutional study. J Clin Oncol 2004;22:3284-92.

19. Elias D, Gilly F, Boutitie F, Quenet F, Bereder JM, Mansvelt B, Lorimier G, Dubè P, Glehen O. Peritoneal colorectal carcinomatosis treated with surgery and perioperative intraperitoneal chemotherapy: retrospective analysis of 523 patients from a multicentric French study. J Clin Oncol 2010;28:63-8.

20. Elias D, Faron M, Goéré D, Dumont F, Honoré C, Boige V, Malka D, Ducreux M. A simple tumor load-based nomogram for surgery in patients with colorectal liver and peritoneal metastases. Ann Surg Oncol 2014;21:2052-8.

21. Allard MA, Adam R, Ruiz A, Vibert E, Paule B, Levi F, Sebagh M, Guettier C, Azoulay D, Castaing D. Is unexpected peritoneal carcinomatosis still a contraindication for resection of colorectal liver metastases? Combined resection of colorectal liver metastases with peritoneal deposits discovered intra-operatively. Eur J Surg Oncol 2013;39:981-7.

22. Dunne DF, Gaughran J, Jones RP, McWhirter D, Sutton PA, Malik HZ, Poston GJ, Fenwick SW. Routine staging laparoscopy has no place in the management of colorectal liver metastases. Eur J Surg Oncol 2013;39:721-5.

23. Khan AZ, Karanjia ND. The impact of staging laparoscopy prior to hepatic resection for colorectal metastases. Eur J Surg Oncol 2007;33:1010-3.

24. Cao C, Yan TD, Black D, Morris DL. A systematic review and metaanalysis of cytoreductive surgery with perioperative intraperitoneal chemotherapy for peritoneal carcinomatosis of colorectal origin. Ann Surg Oncol 2009; 16:2152-65.

25. Esquivel J. Technology of hyperthermic intraperitoneal chemotherapy in the United States, Europe, China, Japan, and Korea. Cancer J 2009; $15: 249-54$

26. Carmignani CP, Ortega-Perez G, Sugarbaker PH. The management of synchronous peritoneal carcinomatosis and hematogenous metastasis from colorectal cancer. Eur J Surg Oncol 2004;30:391-8.

27. Kianmanesh R, Scaringi S, Sabate JM, Castel B, Pons-Kerjean N, Coffin B, Hay JM, Flamant Y, Msika S. Iterative cytoreductive surgery associated with hyperthermic intraperitoneal chemotherapy for treatment of peritoneal carcinomatosis of colorectal origin with or without liver metastases. Ann Surg 2007;245:597-603.

28. Franko J, Gusani NJ, Holtzman MP, Ahrendt SA, Jones HL, Zeh HJ 3rd, Bartlett DL. Multivisceral resection does not affect morbidity and survival after cytoreductive surgery and chemoperfusion for carcinomatosis from colorectal cancer. Ann Surg Oncol 2008;15:306572 .

29. Varban O, Levine EA, Stewart JH, McCoy TP, Shen P. Outcomes associated with cytoreductive surgery and intraperitoneal hyperthermic chemotherapy in colorectal cancer patients with peritoneal surface disease and hepatic metastases. Cancer 2009;115:3427-36.

30. Duraj FF, Cashin PH. Cytoreductive surgery and intraperitoneal chemotherapy for colorectal peritoneal and hepatic metastases: a casecontrol study. J Gastrointest Oncol 2013;4:388-96.

31. Chua TC, Yan TD, Zhao J, Morris DL. Peritoneal carcinomatosis and liver metastases from colorectal cancer treated with cytoreductive surgery perioperative intraperitoneal chemotherapy and liver resection. Eur J Surg Oncol 2009;35:1299-305.

32. Navez J, Remue C, Leonard D, Bachmann R, Kartheuser A, Hubert C Coubeau L, Komuta M, Van den Eynde M, Zech F, Jabbour N. Surgical treatment of colorectal cancer with peritoneal and liver metastases using combined liver and cytoreductive surgery and hyperthermic intraperitoneal chemotherapy: report from a single-centre experience. Ann Surg Oncol 2016;23:666-73.

33. Chua TC, Yan TD, Saxena A, Morris DL. Should the treatment of peritoneal carcinomatosis by cytoreductive surgery and hyperthermic intraperitoneal chemotherapy still be regarded as a highly morbid procedure: a systematic review of morbidity and mortality. Ann Surg 2009;249:900-7.

34. House MG, Ito H, Gönen M, Fong Y, Allen PJ, DeMatteo RP, Brennan MF, Blumgart LH, Jarnagin WR, D’Angelica MI. Survival after hepatic resection for metastatic colorectal cancer: trends in outcomes for 1,600 patients during two decades at a single institution. $J$ Am Coll Surg 2010;210:744-52, 752-5.

35. Paun BC, Cassie S, MacLean AR, Dixon E, Buie WD. Postoperative complications following surgery for rectal cancer. Ann Surg 2010;251:807-18.

36. Elias D, Benizri E, Pocard M, Ducreux M, Boige V, Lasser P. Treatment of synchronous peritoneal carcinomatosis and liver metastases from colorectal cancer. Eur J Surg Oncol 2006;32:632-6. 